This is not the definitive version of the text.

Please cite this article as: Cuadrado, E., Tabernero, C., \& Briones, E. (2014). Dispositional and psychosocial variables as longitudinal predictors of acculturative stress. Applied Psychology: An International Review, 63 (3), 441-479. doi: 10.1111/j.1464-0597.2012.00531.x

\title{
Dispositional and Psychosocial Variables as Longitudinal Predictors of Acculturative Stress
}

\author{
Esther Cuadrado* and Carmen Tabernero \\ University of Cordoba, Spain \\ Elena Briones \\ University of Cantabria, Spain
}

\begin{abstract}
As societies become more multicultural, citizens need to develop selfregulatory mechanisms in order to successfully cope with the increasing levels of psychosocial stress related to acculturation. In this study, a longitudinal theoretical model was tested in order to evaluate the role of implicit theories of cultural intelligence, causal attributions, perceived social support, and cultural identity as predictors of acculturative stress. The research was carried out in Spain across three consecutive years with a multicultural sample of 292 students (natives and immigrants). The results confirm the proposed theoretical model using multi-group structural equation modelling to test the equivalence of the longitudinal causal structure in immigrants and natives. Moreover, mediation analyses confirmed the mediating effect of cultural identity between the implicit theories of cultural intelligence and acculturative stress, as well as the mediating effect of perceived social support between causal attributions and acculturative stress. The model indicates the relevance of promoting psychosocial interventions with native and immigrant adolescents in intercultural contexts. In those interventions, it will be relevant to promote incremental implicit theories of cultural intelligence and internal causal attributions, as well as to highlight a more intercultural identity and to encourage greater social support networks.
\end{abstract}

* Address for correspondence: Esther Cuadrado and Carmen Tabernero, University of Cordoba, Department of Psychology, Calle San Alberto Magno s/n, 14071 Córdoba, Spain. Email: esther.cuadrado@uco.es or carmen.tabernero@uco.es

The data collection was financially supported by the Spanish Ministry of Science and Technology Grant number PSI 2009-07423, in which Carmen Tabernero is the main researcher. And the manuscript was written while Esther Cuadrado was a fellow doctoral researcher financially supported by the Spanish Educational Ministry within the framework of the National Programme of university teacher training (2010-2014). We also thank the anonymous reviewers for their helpful comments and David L. Palenzuela for his assistance on the relations of the attributional processes. 


\section{INTRODUCTION}

In an increasingly multicultural modern society, research on acculturative stress seems to be relevant, considering that acculturative stress is related to multiple negative psychological outcomes such as unhappiness and negative affect (Shin, Han, \& Kim, 2007), critical levels of psychological well-being (Cho \& Haslam, 2010), anxiety, depressive symptoms, depression (e.g. Mejía \& McCarthy, 2010), suicidal ideations (Cho \& Haslam, 2010), and suicidality (Lipsicas \& Mäkinen, 2010).

Based on the Cognitive Affective Personality System theory (CAPS; Mischel \& Shoda, 1995; Mendoza-Denton, Ayduk, Mischel, Shoda, \& Testa, 2001), we analysed the role of some dispositional and psychosocial variables in predicting acculturative stress over time, as well as the potential relations between those predictors. The CAPS proposes an interactive, dynamic, and meta-theoretical model which conceives of the individual as a complex processing system. This model suggests that the situation and the cognitive, affective, and personality components interact together as a whole, and that this interaction leads individuals to behave in a specific way. Moreover, it explains how dispositional and self-regulatory mecha- nisms are reciprocal with regard to outcome behaviours: negative personal, emotional, and adaptive mechanisms predict negative outcomes which, in turn, predict negative personal, emotional, and adaptive mechanisms. And in the CAPS the outcome behaviours result from dynamic personenvironment transactions (Cervone, 2005). In other words, people are A when the situation is $\mathrm{X}$, but B when the situation is $\mathrm{Y}$ (Mendoza-Denton et al., 2001), and the dispositional and self-regulatory mechanisms along with the personality qualities are interconnected mediators which lead indi- viduals to determined behaviours.

As stated by Shoda and Mischel (2006), the selection as to which one of the possible mediators is important in the CAPS to determine a behaviour depends on the individual, on the behaviour one is interested in predicting, and on the situation within which these behaviours are expected to occur. Moreover, as Cervone (2005) illustrates, "diverse lines of experimental research illuminate the functional relations among enduring mental structures and dynamic personality processes" (p. 441), and the knowledge structures (as the dispositional variables) causally influence appraisal processes (such as some psychosocial variables). Thus, in an acculturative context, and when the interest is in predicting acculturative stress in adolescents, some variables widely studied in the past (e.g. Cho \& Haslam, 2010; Roddenberry \& Renk, 2010; Rusk \& Rothbaum, 2010) in relation to the acculturative contexts (such as the dispositional and psychosocial variables of this study) seem to be potentially interconnected mediators to those employed in the CAPS approach to predicting acculturative stress.

According to both Lazarus and Folkman's perspective on stress (1984) 
and Berry's views on acculturation (2003, 2005), acculturative stress can be defined as a particular relationship between a person and his or her intercultural environment (with its sub-consequent changes) that is appraised as exceeding the existing self-resources and endangering the person's well-being. In accordance with Berry's conceptualisation (2005), acculturative stress occurs when both natives and immigrants perceive that situations involving intercultural contact will give rise to threats, changes, conflicts, and challenges that cannot easily be resolved through simple behavioural adjustments. Thus, acculturative stress occurs when people perceive high cultural conflict and feel that they have limited resources with which to deal with the situation. Although many of the changes resulting from acculturative processes are not generally perceived as being stressful, the different values, customs, and norms of different groups can bring about difficulties, and sometimes a degree of cultural conflict emerges that may lead to acculturative stress (Berry, 2005).

Acculturative stress tends to decrease over time, as individuals adjust to the intercultural context (e.g. Tartakovsky, 2007; Ying, 2005). And, the acculturative process is easier for young people (who have more phenotypic plasticity and whose identity is under construction in their intercultural context) than in adults (e.g. Cheung, Chudek, \& Heine, 2011; Schwartz, Unger, Zamboanga, \& Szapocznik, 2010). Moreover, acculturative processes occur in both natives and immigrants, but have a greater effect on the immigrant group (Berry, 2005; Mejía \& McCarthy, 2010).

There have also been abundant studies showing that several variables are related to stress and acculturative stress (e.g. Schwartz et al., 2010). The CAPS explains that some important mediators interact to influence each determinate behaviour scholars are interested in predicting (Shoda \& Mischel, 2006). Furthermore, Berry (2005) has suggested the relevance of studying which variables could act as longitudinal predictors of acculturative stress across both groups (immigrants and natives).

In this sense, this study is relevant because it responds to an important gap in the literature regarding stress and acculturative stress. As highlighted by Zapf, Dormann, and Frese (1996), the bulk of empirical research about predictors of acculturative stress are cross-sectional and thus are not able to explain the predictive power of the variables on acculturative stress over time, or to demonstrate causal relations in such designs, being only correlational. In the same way, Fuligini (2001) notes that acculturative processes have often been considered in cross-sectional studies which ignore the value of time in such processes. This author and others (e.g. Duru \& Poyrazli, 2007; Paukert, Pettit, Perez, \& Walker, 2006) have highlighted that further longitudinal designs are needed in acculturative stress research. Although more longitudinal studies about acculturative processes have been published in recent years, they are still few in number, and in general they are more descriptive works (e.g. Cemalcilar, 2008; Ying, 2005) that focus on anxiety, depression, psychiatric symptoms, or other processes related to acculturation, but not 
specifically on acculturative stress (e.g. Araújo Dawson \& Williams, 2008; Duarte, Bird, Shrout, Wu, Lewis-Fernandez, Shen, \& Canino, 2008), or focus on the effect that acculturative stress has on other behaviours and outcomes (e.g. Walker, 2007). Nevertheless, few of them focus on the potential precursors of acculturative stress and psychological adjustment in the acculturative context (e.g. Tartakovsky, 2007; Ying \& Han, 2006).

Thus, our study is an attempt to respond to this gap by using alongitudinal design. This methodology should enable us to (a) demonstrate causal inferences of the predictors of acculturative stress; (b) explore the mediating role of some variables with regard to acculturative stress; and (c) reduce the problems associated with cross-sectional studies of reverse causation and the treatment of third variables.

Therefore, the main purpose of this study is to analyse the role of dispositional and psychosocial variables as longitudinal predictors of acculturation stress. The selection of the dispositional and psychosocial variables examined is related to the importance given to these kinds of variables as potential mediators which interact to determine behaviour in the framework of the CAPS (Mischel \& Shoda, 1995; Mendoza-Denton et al., 2001).

\section{Dispositional Variables}

From the perspective of the CAPS (Mischel \& Shoda, 1995; MendozaDenton et al., 2001), dispositional variables are part of the personality system which interact with other variables and thus predict behaviour. In this study we analysed the predictive power of two dispositional variables that across the literature have been related to stress.

Implicit Theories of Cultural Intelligence. Since motivational socialcognitive theory was propounded (Dweck, 1999), many studies have shown that, while incremental theorists (who believe that intelligence can be developed) tend to adopt mastery-oriented patterns and achieve more positive outcomes (Kaplan \& Maehr, 2007), entity theorists (who believe that intelligence cannot be developed) tend to adopt helpless patterns and achieve negative outcomes in different areas. These areas include academic and nonacademic self-efficacy and performance (Blackwell, Trzesniewski, \& Dweck, 2007; Tabernero \& Wood, 1999), socio-emotional functioning (Tamir, John, Srivastava, \& Gross, 2007), stereotyping processes with regard toindividuals (Chiu, Dweck, Tong, \& Fu, 1997) and groups (Levy, Stroessner, \& Dweck, 1998), conflict resolution processes (Dweck \& Ehrlinger, 2006), emotional states and self-reported crying behaviours (van Tilburg, Becht, \& Vingerhoets, 2003), and self-defensive responses in potentially stressful situations (Rusk \& Rothbaum, 2010).

In relation to cross-cultural interactions and acculturative stress, implicit 
theories of cultural intelligence seem to be of greater interest than the implicit theories about intelligence. Cultural intelligence is "a vitally important aptitude and skill" in a multicultural context, and a "natural ability to interpret someone's unfamiliar and ambiguous gestures in just the way that person's compatriots and colleagues would, even to mirror them" (Earley \& Mosakowski, 2004, p. 139). On this basis, cultural intelligence has been definedas a type of multifaceted intelligence and a multidimensional construct conceived as "a system of interacting knowledge and skills, linked by cultural metacognition, that allows people to adapt to, select, and shape the cultural aspect of their environment” (Thomas, Elron, Stahl, Ekelund, Ravlin, Cerdin, Poelmans, Brislin, Pekerti, Aycan, Maznevski, Au, \& Lazarova, 2008, p. 127). Thus we can conceive of cultural intelligence as the ability to adapt successfully to the multicultural environment; therefore, it seems rel- evant to assess whether or not implicit theories of cultural intelligence can be related to acculturative stress in our intercultural societies.

In line with the results of studies on implicit theories, we propose that fixed implicit theories of cultural intelligence (or the belief that adaptation capacity is fixed) lead individuals to adopt helpless patterns and thus to suffer more stress in acculturative conditions. We anticipated that adolescents with fixed implicit theories of cultural intelligence would suffer more acculturative stress than those with incremental implicit theories of cultural intelligence; in other words, we hypothesised that:

Hypothesis 1: Fixed implicit theories of cultural intelligence will positivelypredict future acculturative stress.

Causal Attributions. Lazarus and Folkman's (1984) model of stress attributes great importance to the cognitive and subjective appraisal of situations. In this sense, people can perceive and attribute to internal (as the result of the resources and behaviours of the person such as ability and effort) or external (as the result of fate, luck, difficulty of the task, or other people) causes affecting them or others, as well as success and failure (Weiner, 1985). According to Weiner (1985), the first dimension of causal attributions is therefore the locus of control, whether internal or external. As such, many authors have demonstrated that causal attributions could have an influence on stress and psychological ill-being (e.g. Roddenberry \& Renk, 2010; Scott, Carper, Middleton, White, Renk, \& Grills-Taquechel, 2010), on psychological adjustment to illness (Oba, Takatsuka, Nagata, Nagao, Yamamoto, Shibuya, Kashiki, \& Shimizu, 2009), on emotional distress (e.g. 
Faller, Schilling, \& Lang, 1995), on job stress (Siu, Spector, Cooper, Lu, \& $\mathrm{Yu}, 2002)$, and on stress in acculturative conditions (e.g. Arslan, Dilmaç, \& Hamarta, 2009). In line with this assessment, Hovey and Magaña (2002) confirmed the protective role of perceptions of control on immigrants' levels of anxiety and depression. It therefore seems that, with internal causal attributions, individuals perceived more control and therefore suffered less stress in difficult situations than those with external causal attributions.

Consequently, from the point of view of the acculturative context, and on the basis of these findings, we propose that adolescents with higher external causal attributions will suffer higher levels of acculturative stress than those with lower external causal attributions; in other words, we hypothesised that:

Hypothesis 2: External causal attributions will positively predict future acculturative stress.

\section{Psychosocial Variables}

Perceived Social Support. According to the CAPS (Mischel \& Shoda, 1995; Mendoza-Denton et al., 2001), we can conceptualise perceived social support as a potential mediator, which is part of the cognitive and affective system and which interacts with other variables to predict behaviour. In the early days, social support was perceived as a mechanism for coping with stress and as a stress moderator and protective factor against depression in the face of extensive life changes (Cobb, 1976). Note that research on stress attaches great importance to cognitive appraisals (Berry, Phinney, Sam, \& Vedder, 2006; Lazarus \& Folkman, 1984); thus, perceived social support, as "the cognitive appraisal of being reliably connected to others" (Barrera, 1986, p. 416), could be a key variable in acculturative stress studies.

And analysing the link between perceived social support and other dispositional variables of the model, research (e.g. Zea, Jarama, \& Bianchi, 1995) has shown that internal causal attributions (another acculturative stressrelated variable, as discussed) facilitate greater accessibility to social support. Moreover, in the same way, some authors (e.g. Cauce, Hannan, \& Sargeant, 1992; VanderZee, Buunk, \& Sanderman, 1997) found a relation between causal attributions and social support in coping with stress, demonstrating that people with internal causal attributions draw more benefits from social support and perceived a greater degree of social support than those with external causal attributions. And research has highlighted that personality traits influence perceived social support. Thus, people interpret social support in line with their own beliefs (Sarason, Pierce, \& Sarason, 1990). Consequently, the belief schemes created in childhood influence later social support (e.g. Green \& Rodgers, 2001; Henly, Danziger, \& Offer, 2005). 
People with external causal attributions tend to perceive lower amounts of social support (Daniels \& Guppy, 1997; Sinibaldi, 2001). And internal causal attributions are also related to more efficient coping strategies, feelings of competence, and better well-being (e.g. Daniels \& Guppy, 1997). Moreover, it is noteworthy that it has been shown that people who believe that they can control the results and events of their own life (i.e. people with internal causal attributions) perceive high levels of social support, whereas those who believe that the results and events of their life are out of their control tend to perceive lower levels of social support (e.g. Lakey \& Cassady, 1990; Sarason et al., 1990).

Returning to the perceived social support-stress link, hypersensitivity to social rejection was related to perceived levels of stress (Ronen \& Baldwin, 2010), social connectedness was found to be a predictor of acculturative stress (Duru \& Poyrazli, 2007), and stronger family ties were related to greater well-being in native and immigrant samples (Arends-Tóth \& Van de Vijver, 2008). Moreover, studies with immigrants demonstrated the importance of social support in acculturative processes (e.g. Martínez, García, \& Maya, 2002). For example, Crockett, Iturbide, Torres Stone, McGinley, Rafaelli, and Carlo (2007) showed that social support reduces acculturative stress in Mexican-American students. In addition, indicators of psychological adaptation in acculturative situations were related in different cultural groups with contact frequency (Griffith, 1984), social support networks (e.g. Martínez et al., 2002), family social support (e.g. Cho \& Haslam, 2010; Rodríguez, Mira, Páez, \& Myers, 2007), social support from adolescents’ peers (e.g. Crockett et al., 2007), received social support (e.g. Gençoz \& Astan, 2006; Zea et al., 1995), perceived social support (Gençoz \& Astan, 2006), and perceived social support from peers and teachers (Tartakovsky, 2007). In all of these studies, the social support being analysed promoted better psychological adaptation.

Social Support was first investigated as a protective factor from stress, and many subsequent studies have demonstrated a strong negative predictive relation between social support and stress and between social support and different indicators of adaptation and psychological well-being in acculturative contexts (e.g. Cho \& Haslam, 2010). Note that Tartakovsky (2007) showed in a longitudinal study that perceived social support was negatively correlated with acculturative stress. Thus, we projected that perceived social support and acculturative stress would evolve according to opposite trends over time: as perceived social support increases, acculturative stress will decrease. Therefore, we proposed that-in the same way that acculturative stress decreases as individuals adjust to their new cultural environment (e.g. Tartakovsky, 2007; Ying, 2005)—perceived social support would become stronger as the intercultural contact is naturalised and as individuals become more effective within the intercultural relationship processes. 
We thus expected that adolescents with greater external causal attributions would perceive lower social support levels than those with lower external causal attributions (e.g. Lakey \& Cassady, 1990; Sarason et al., 1990). In turn, we expected that adolescents with higher levels of perceived social support would develop lower levels of acculturative stress than those with lower levels of perceived social support (e.g. Arends-Tóth \& Van de Vijver, 2008; Cho \& Haslam, 2010; Gençoz \& Astan, 2006; Martínez et al., 2002). In other words, we hypothesised that:

Hypothesis 3: Perceived social support will mediate the association between causal attributions and acculturative stress.

Cultural Identity. Research on acculturation has also focused on cultural identity, meaning the part of the self-concept that integrates the importance, value, and emotional significance of belonging to and identifying with a specific cultural group (Tajfel, 1981). Cultural identity is constructed in relation to the broader cultural group in which the individual is immersed, and therefore it can be modified in intercultural contexts. Nevertheless, identity factors and core self-evaluations (such as cultural identity) tend to be relatively stable over time (e.g. Hirschi, 2011) when intercultural contexts remain stable. Accordingly, cultural identity is unlikely to undergo significant changes between the different evaluation points.

As stated by the CAPS (Mischel \& Shoda, 1995; Mendoza-Denton et al., 2001), the cognitive, affective, and personality components of the individual are part of the potential mediators that determine human behaviour, and with regard to predicting acculturative stress, the studies have shown that cultural identity can be a potential predictor of this particular behaviour.

Although many authors have viewed cultural identity as a protectivefactor with regard to acculturative stress (e.g. Rodríguez et al., 2007) in perceived discrimination situations (e.g. Paradies, 2006), the results of the investigations have been contradictory. The extant literature does not demonstrate clearly that higher levels of cultural identity buffer the effects of racial discrimination in individuals' psychological adjustment (Yoo \& Lee, 2008). Furthermore, many studies have shown that, in contrast, cultural identity acts as a risk factor for anxiety, depression (Hovey, Kim, \& Seligman, 2006), and stress in immigrants (Sánchez \& Fernández, 1993), and worsens the negative effects of frequent racial discrimination on well-being (Friedlander, Friedman, Miller, Ellis, Friedlander, \& Mikhaylov, 2010; Yoo \& Lee, 2008). Authors have concluded that a high degree of identification with one's own cultural group could result in difficulties, contributing to psychological distress when the values of the cultural in-groups and out-groups contradict one another (Hovey et al., 2006), or when individuals perceive discrimination 
(Friedlander et al., 2010; Yoo \& Lee, 2008). It seems, then, that a higher degree of identification with the cultural in-group makes individuals more vulnerable to acculturative processes and to perceiving such processes as a threat. In this sense, some authors have demonstrated that "more traditional family values were associated with less well-being" (Arends-Tóth \& Van de Vijver, 2008, p. 480).

Therefore, in this research we respond to a lack in previous literature: the clear contradiction in studies regarding whether cultural identity is a protective or a risk factor of acculturative stress (Yoo \& Lee, 2008).

Furthermore, following Dweck and colleagues'studies (e.g. Dweck, 1999) on implicit theories of intelligence, most authors (e.g. Chiu et al., 1997; Heine \& Ruby, 2010; Heine, Kitayama, Lehman, Takata, Ide, Leung, \& Matsumoto, 2001; Hong, Ip, Chiu, Morris, \& Menon, 2001; Shweder \& Miller, 1985) found that some differences between cultures are owed, at least in part, to the different implicit theories held by the individuals. For example, Heine et al. (2001) have shown that North Americans have a less selfimproving orientation than Japanese. They demonstrated that this difference in persistence in a follow-up task is owed to different individual implicit theories of ability (the belief that different individuals' abilities — such as their intelligence-are incremental or fixed). They argued that "one reason for the two cultural groups' different reactions to success and failure is that Japanese individuals are more likely to view their self and their performance as potentially improvable" (Heine et al., 2001, p. 606). Moreover, they showed that Japanese believed that abilities were more incremental than European Americans did.

In the same way, Shweder and Miller (1985) found that Americans placed more importance on their personal identity, while Asiatic individuals placed more emphasis on their cultural identity. Accordingly, with regard to the mediating relations between the dispositional and psychosocial variables conceptualised in the CAPS (Mischel \& Shoda, 1995; Mendoza-Denton et al., 2001), some authors (e.g. Bastian \& Haslam, 2008; Chiu et al., 1997; Hong et al., 2001) claim that this difference lies in the implicit theories held by the individuals. Bastian and Haslam (2008) explained that people with fixed implicit theories about the human character perceived social identities as rigid and static, whereas people with malleable implicit theories about the human character perceived social identities as dynamic and changeable. They suggested that entity theorists are more likely to use these social identities in the construction of their self than are incremental theorists. In this sense, Tong and Chang (2008) showed that individuals who endorse higher group entity beliefs or fixed implicit theories about social identity (meaning the beliefs that social identities cannot change) (a) exhibit stronger social identity effects than individuals with incremental implicit theories; (b) identify themselves with their in-group to a greater extent; and (c) stay strongly, stably, and 
enduringly attached to their groups, which remain an essential part of their self-definition.

Hong, Chan, Chiu, Wong, Hansen, Lee, Tong, and Fu (2003) also demonstrated that, with fixed implicit theories, individuals were more likely than incremental theorists to attribute to themselves the qualities of the group they belong to. This means that individuals with fixed implicit theo- ries use their social identity to guide their self-conception, whereas incre- mental theorists tend not to use it as much for this purpose (Hong et al.,2003). The authors found that, with fixed implicit theories, individuals con- sidered their social identity (e.g. cultural identity) as more important, and wanted to be clearly differentiated from out-groups. Moreover, No, Hong, Liao, Lee, Wood, and Chao (2008) illustrated that fixed implicit theories of race (the belief that race is a stable essence and indicative of traits) orient people to adhere rigidly to their cultural group and to show less out-group identification. And finally, Dar-Nimrod and Heine (2011) explained that maintained fixed implicit theories about the intelligence of people increases the perceived homogeneity and immutability of the groups' members. Thus, and in agreement with all those studies, we argue that the belief that membership of a special group and cultural intelligence is immutable and in a way "genetic" can influence people to maintain a higher cultural identity than people who think that those personal characteristics can change.

In addition, as we have seen, cultural identity is also related to acculturative stress (e.g. Friedlander et al., 2010; Hovey et al., 2006; Yoo \& Lee, 2008). Therefore, it seems that implicit theories could influenceacculturative stress not only directly (in line with the results of the multiple studies about implicit theories, as for example those of Dweck, 1999; Rusk \& Rothbaum, 2010; and Tamir et al., 2007), but also indirectly, by the effects that these theories have on cultural identity (increasing cultural identity levels, as can be deduced from the studies by Dar-Nimrod \& Heine, 2011; Bastian \& Haslam, 2008; and Tong \& Chang, 2008), which in turn predicts acculturative stress (e.g. Friedlander et al., 2010; Hovey et al., 2006; Yoo \& Lee, 2008). Thus, we expected that those adolescents with fixed implicit theories of cultural intelligence would develop higher cultural identity than those with incremental implicit theories of cultural intelligence (e.g. Dar-Nimrod \& Heine, 2011; Bastian \& Haslam, 2008; Tong \& Chang, 2008) and that, in turn, adolescents with high cultural identity would develop more acculturative stress than those with low cultural identity (e.g. Friedlander et al., 2010; Hovey et al., 2006; Yoo \& Lee, 2008). In other words, we hypothesised that:

Hypothesis 4: Cultural identity will mediate the association between implicit theories of cultural intelligence and acculturative stress. 
In other matters, "a growing body of work indicates that social support is more likely to be given, received, and interpreted in the spirit in which it is intended to the extent that those who are in a position to provide and receive that support perceive themselves to share a sense of social identity" (Haslam, Jetten, Postmes, \& Haslam, 2009, p. 11) as occurs in their own cultural group.

Accordingly, it has been demonstrated that when people strongly identify themselves with a particular group, social support increases between group members, and thereby stress levels decrease (Haslam, Jetten, O’Brien, \& Jacobs, 2004; Haslam, O’Brien, Jetten, Vormedal, \& Penna, 2005; Kellezi, Reicher, \& Cassidy, 2009; Reicher \& Haslam, 2006). For example, Haslam et al. (2004) found that only when people share the same collective identity and identify themselves with a particular group is the social support that they offer likely to prove beneficial in stressful situations, and that the positive effects of social support emerge only when people share a common collective identity. And Reicher and Haslam (2006) have shown that a high collective identity led people to mutual social support, and thus to greater well-being.

Moreover, Kellezi et al. (2009) have shown that Kosovians who survived the 1999 Kosovo conflict suffered less stress when that conflict was identity affirming rather than identity negating because common identity led them to greater social support from their in-group members. Furthermore, Haslam et al. (2005) found that high collective identification acts as a protective factor for stress in the group members because it provides a basis from which to receive and benefit from social support; those authors (Haslam et al., 2005) demonstrated in two different studies that social support mediates the relation between collective identification and different kinds of stress.

And although sharing a common collective identity is not exactly the same as according great importance to the self-concept of belonging to and identifying with a specific cultural group (having a high cultural identity), it seems clear, however, that, with a high cultural identity, people of a specific group share a common identity and tend to identify themselves with this group. Therefore, if sharing a common collective identity and identifying oneself with a particular group is related to perceived social support (Haslam et al., 2009), we argue that people with high cultural identity probably tend to perceive more social support than those with low cultural identity. Moreover, in this sense Rodríguez et al. (2007) have shown that individuals who attribute greater importance to their cultural identity in a Mexican sample tend to perceive geater family social support. And Haslam et al. (2005) found in their first and second studies that perceived social support mediates the relation between social identification and stress. Indeed, they found that when people identify themselves strongly with a particular group (with a high cultural identity) they perceive greater social support and thus they suffer less stress. In addition, the propensity to cultivate to a greater extent the con-struction of a global identity has also been related to a higher perception of 


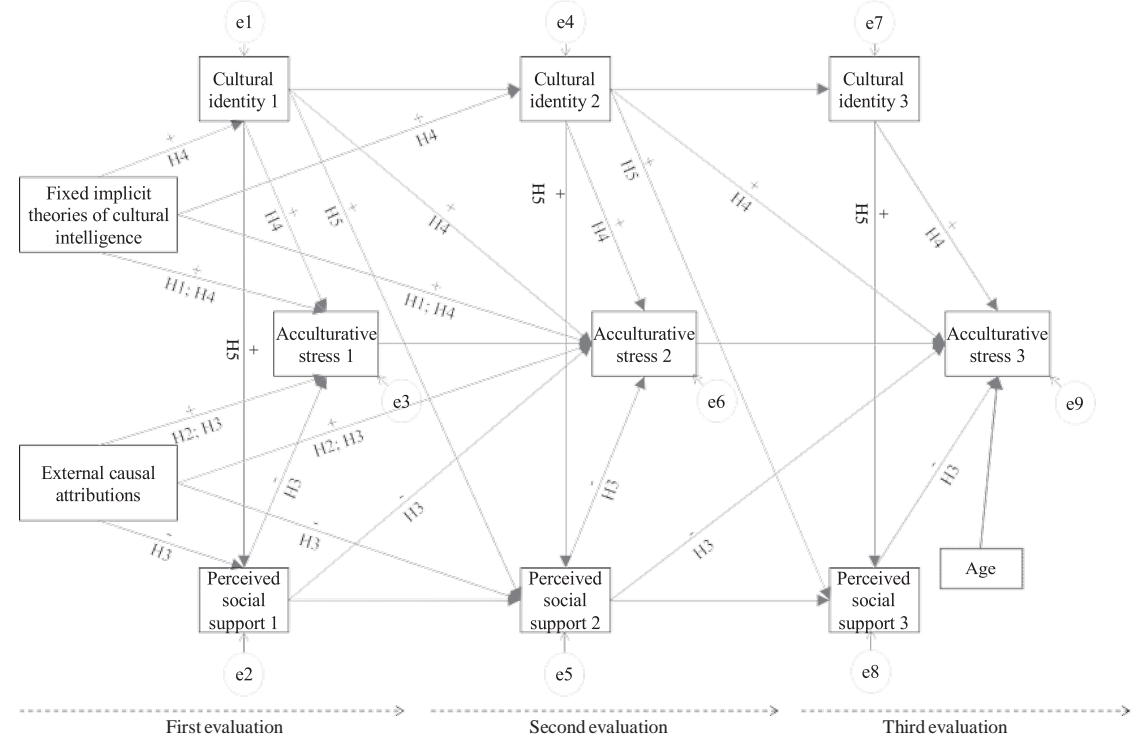

FIGURE 1. A hypothetical model presenting how dispositional and psychosocial variables influence acculturative stress across time. Circles reflect error terms. Age was included as a covariate to control for age variation.

social support (Ng \& Feldman, 2009). Thus, several studies have related perceived social support with identity, demonstrating that collective and cultural identities are good predictors of social support; a basis for social support.

Thus, we projected that with higher levels of cultural identity individuals will perceive higher levels of social support than those with lower levels of cultural identity; so we propose that:

Hypothesis 5: A high cultural identity will predict greater perceived social support.

In short, concerning the interrelation between the variables, we hypothesised that: (a) across time both dispositional variables (implicit theories of cultural intelligence and external causal attributions) directly predict acculturative stress; (b) perceived social support is a potential mediator between causal attributions and acculturative stress; (c) cultural identity is a potential mediator between implicit theories of cultural intelligence and acculturative stress; and (d) cultural identity directly predicts perceived social support (see Figure 1). 


\section{The Present Study}

The global aim of our study was to analyse the role of some dispositional (implicit theories of cultural intelligence and causal attributions) and psychosocial variables (perceived social support and cultural identity) in predicting acculturative stress across time, and to analyse the relation between those predictors themselves by testing the potential mediating effect of perceived social support between causal attributions and acculturative stress, as well as the potential mediating effect of cultural identity between implicit theories of cultural intelligence and acculturative stress, in accordance with the CAPS (Mishel \& Shoda, 1995; Mendoza-Denton et al., 2001). Our design, over a large sample of adolescents, comprised three measurement points with a 10-month interval between the first and second assessments, and with a 7month interval between the second and third assessments, in accordance with the availability of the participating secondary schools.

We chose the variables in line with the framework within which this study is conducted. The CAPS (Mischel \& Shoda, 1995; Mendoza-Denton et al., 2001) discusses interconnected mediators which predict individuals' behaviour, and Shoda and Mischel (2006) explain that the relevance of one or other mediator depends in part on the behaviour scholars are interested in predicting. As such, the dispositional (implicit theories of cultural intelligence and causal attributions) and psychosocial variables (perceived social support and cultural identity) chosen for this study have been commonly related to acculturative stress in previous literature, thus supporting our choice.

The potential of this study lies in two objectives: first, it is a longitudinal study, and so responds to a gap in the previous literature (based almost exclusively on cross-sectional investigations) and to the need for more longitudinal studies about acculturative stress (e.g. Duru \& Poyrazli, 2007; Paukert et al., 2006); second, it attempts to respond to an important contradiction in past literature regarding whether cultural identity acts as a protective or a risk factor on acculturative stress (Yoo \& Lee, 2008).

Thus, the analysis of such variables (most commonly studied in previous cross-sectional literature) as longitudinal predictors of acculturative stress, and the testing of the potential relations between them, seems to be relevant from the theoretical perspective. Moreover, from the perspective of application, in an increasingly multicultural and acculturated world, and with the understanding of the potentially disastrous results of high acculturative stress (e.g. Cho \& Haslam, 2010; Lipsicas \& Mäkinen, 2010), it seems relevant to study which variables can be predictors of acculturative stress, and then propose some practical interventions based on the results to reduce this psychological distress. 


\section{METHOD}

\section{Participants}

A total of 1,106 adolescents from six randomly selected multicultural Spanish public secondary schools participated in this study. However, for the longitudinal study, we used only the responses of those participants who completed the questionnaire at all three measurement points. Also, in order to avoid bias in the analysis, we eliminated those questionnaires in which participants stated that their level of Spanish fluency was very low. Consequently, a total of 292 students participated in this longitudinal study (52.7\% boys and $47.3 \%$ girls). The age range was between 12 and 18 years old for boys and between 12 and 17 years old for girls $(M=14.77, S D$ $=.94 ;$ Mboys $=14.91$, SDboys $=.99 ;$ and Mgirls $=14.61$, SDgirls $=$ .87).

The adolescents were natives of 20 different countries: 64.7 per cent were born in Spain and 35.3 per cent were born abroad (America, 20.2\%; Africa, 8.2\%; Europe, 4.8\%; Asia, 2.1\%). A total of 59.2 per cent of the participants had parents (both mother and father) who were born in Spain, and 40.8 per cent had at least one parent who was born abroad. Consequently, in agreement with the conception of native versus immigrant of Berry et al. (2006), 59.2 per cent of the participants were natives (born in Spain with a native Spanish father and mother) and 40.8 per cent were immigrants (born in Spain to an immigrant father or/and mother, or born in another country).

We also performed analyses in order to check whether the students who finished all three surveys (our longitudinal sample of 292 students) were significantly different from those who did not (the rest of the 1,106 students of the total sample). For the combined sample the chi-square analyses performed with contingency tables have shown that, in relation to their background, the proportion of girls and boys who finished all three surveys was no different from that which did not $\left(c^{2}(1,1077)=.17, n s, h^{2}=.01\right)$. Nevertheless, there were differences between natives and immigrants. The immigrants had more risk of not finishing all three surveys than natives had $\left(c^{2}(1,1078)=8.83, p<.01, h^{2}=.09, O R=.66\right)$. The ANOVAs performed showed that (a) students who did not complete all three surveys were significantly $(F(1,1074)=267.96, p<.01)$ older $(M=14.64)$ than those who $\operatorname{did}(M=13.16)$; (b) immigrants $(M=14.37)$ were significantly older $(F(1$, $1102)=9.13, p<.01)$ than natives $(M=14.10)$. Therefore it seems that immigrants and older students have more difficulty in finishing their secondary school career than natives and younger students, respectively. This could be because more immigrants start their secondary school studies at a later age than natives (as the results have shown) and because students who 
start those studies later are already failing at school. Moreover, immigrants have more geographic mobility than natives.

Because there were differences between the group of students that did not finish all three surveys and those that did in terms of whether they were natives or immigrants, we performed comparison analyses of the level of focal variables in time 1 separately for each group. For natives, there were no differences in implicit theories between those who completed all three surveys and those who did not $(F(1,532)=.55$, ns), causal attributions $(F(1,534)=2.08, n s)$, cultural identity $(F(1,530)=3.09$, ns $)$, and acculturative stress $(F(1,518)=.04, n s)$. Those who did not complete all three surveys, however, had levels of perceived social support significantly $(F(1,552)=2.41, p<.05)$ lower $(M=5.39)$ than those who did $(M=5.54)$. This is in line with studies that have related social support and perceived social support to success (e.g. Hogan, Parker, Wiener, Watters, Wood, \& Oke, 2010; Nabi, 2001). Regarding immigrants, there were no differences in implicit theories between those who completed all three surveys and those who did not $(F(1,434)=1.49$, ns $)$, causal attributions $(F(1,457)=1.76$, $n s)$, cultural identity $(F(1,457)=4.00, n s)$, and perceived social support $(F(1$, $505)=2.01$, ns). Those who did not complete all three surveys, however, had levels of acculturative stress significantly $(F(1,431)=6.40, p$ $<.05)$ higher $(M=2.15)$ than those who $\operatorname{did}(M=1.87)$.

\section{Procedure}

A pilot study was first conducted after meeting with centre directors and the faculty (to explain the objectives of the study, to present the questionnaire, and to plan and organise its administration). Following this, and after requesting authorisation from parents concerning their children's participation, questionnaires were administered to the participants in their classrooms. Participants used a mean of one hour to complete the questionnaire, which was administered for three consecutive years by two collaborators who were trained for this purpose, unaware of the study's objectives. These collaborators applied the same protocol in each instance, and were supported by an individual who could translate into Arabic. The wide time margin guaranteed the ecological validity of this study, but also resulted in its high drop-out rate. The dispositional variables (implicit theories of cultural intelligence and causal attributions) were measured only in the first evaluation. This was because personality variables are expected to be stable over time. The other variables were measured in all three evaluations. The confidentiality of the responses and absence of time pressure were ensured. 


\section{Measures}

In order to describe the sample, we collected information on sociodemographic variables: sex, age, country of birth and father's and mother's countries of birth. These variables were not the aim of our study (sex did not show any significant influence on the other studied variables).

Implicit Theories of Cultural Intelligence. Implicit theories of cultural intelligence were measured using five items that explored the participants' beliefs about the malleability of cultural intelligence (i.e. whether it is innate or malleable). The items included in the Appendix were created for the purpose of this study following the recommendations of Dweck (1999, p. 180), and on the basis of the concept of cultural intelligence (Earley \& Mosakowski, 2004). Participants recorded their answers on a 6-point Likert scale ranging from 1 (completely agree) to 6 (strongly disagree). In order to avoid social desirability bias, four items posed a fixed concept of the ability to adapt, while one (which was then recoded) used an incremental concept. In the research developed by Dweck, Chiu, and Hong (1995), a comparison of the reliability of measures of implicit theories of intelligence is presented (alpha oscillates between .94 and .98). Cronbach's alpha for implicit theories of the cultural intelligence measure was .74.

External Causal Attributions. As suggested by Heine et al. (2001), causal attributions were measured by presenting two common scenarios in a school context, which described performance in various competencies. The first scenario showed academic achievement as an innate competence (e.g. "Imagine that Susan scored the highest grade in her history class. Knowing only this information about Susan, please do your best to say what you think is the main reason for her performance in the class"), and the second scenario showed musical achievement as a malleable compe- tence (e.g. "John is a high school student and a good piano player. The best piano player at school had been chosen by the music teacher to play at the school graduation, but she broke her hand and needed to be replaced. Theteacher selected John to take her place. John significantly improved his skills before final school graduation. Please do your best to say what you think is the main reason for his performance in the school graduation”). Participants had to evaluate each scenario by answering two items which suggested possible external reasons for the situation (such as luck and task complexity or teacher's involvement). Students expressed their level of agreement with each item on a 5-point Likert scale, ranging from 1 (strongly disagree) to 5 (strongly agree). The reliability of the external causal attributions variable was moderate $(\mathrm{a}=.66)$ and similar to thatobtained by Heine et al. (2001). The authors explained that "this degree of 
consistency, although modest, is reasonable given the small number of items, the wide array of domains of life sampled, and the diverse question formats used in the scale" (p. 610).

Perceived Social Support. Perceived social support was measured using a brief measure from the second part of the Personal Resource Questionnaire 85 (PRQ85; Weinert, 1987) designed to assess perceived level of social support, while the first part was designed to estimate the number of interpersonal resources. This brief measure is included in a revised version presented as PRQ2000 (Weinert, 2003). In this new version, the reliability estimates indicated that the internal consistency remained stable and adequate, ranging from alpha $=.87$ to .93 . The participants answered 11 items (e.g. "There is someone who loves me and cares about me") on a 7-point Likert scale ranging from 1 (strongly disagree) to 7 (strongly agree). Cronbach's alpha values for reliability were adequate across the three evaluations $\left(a_{1}=.75\right.$; $\left.\mathrm{a}_{2}=.84 ; \mathrm{a}_{3}=.88\right)$.

Cultural Identity. Cultural identity was measured using the four items of Brown's identity scale (1998) in reference to the cultural identity factor. This scale is a brief measure of the Aspects of Identity Questionnaire (AIQ; Cheek, Tropp, Chen, \& Underwood, 1994), and explores the personal, social, and cultural factors that contribute to global identity. The AIQ includes three subscales: personal, social, and cultural identity. The cultural identity scale is in reference to one's group memberships. Cheek et al. (1994) and Tropp and Wright (2001) report an equal alpha coefficient of .68. The participants expressed the level of importance that they attributed to each item (e.g. "My race or ethnic background") for their global self-concept on a 5-point Likert scale ranging from 1 (Not important to my sense of who I am) to 5 (Extremely important to my sense of who I am). Cronbach's alpha values were acceptable $\left(\mathrm{a}_{1}=.69 ; \mathrm{a}_{2}=.68 ; \mathrm{a}_{3}=.71\right)$.

Acculturative Stress. Acculturative stress was measured using a brief measure from the Societal, Attitudinal, Familial, and Environmental scale (SAFE; Mena, Padilla, \& Maldonado, 1987), with 23 items designed to assess the specific stressors of acculturative situations. Participants gave their answers to items (e.g. "It bothers me that family members with whom I am close do not understand my new values") on a 6-point Likert scale from 0 to 5 , where 0 means that the situation in question had never been experienced by the participants and where values from 1 to 5 indicated the degree of stress suffered if the participants have experienced the situation $(1=$ not at all stressful to $5=$ extremely stressful). The SAFE scale has been commonly used to evaluate acculturative stress. In the research developed by Mena et al. 
(1987), the Cronbach's alpha coefficient was high $(\mathrm{a}=.85)$ and in our study Cronbach's alpha values were high across the three evaluations $\left(a_{1}=.92\right.$; $\left.\mathrm{a}_{2}=.91 ; \mathrm{a}_{3}=.91\right)$.

\section{Statistical Analyses}

Preliminary Analyses. In order to test the means and standard deviations of the variables of the study, as well as the interactions between them in response to the first and second hypotheses, some descriptive analyses and correlation tests including all evaluation points of all the variables were performed. Moreover, although we have not made any assumptions regarding the evolution of the variables of the study over time, it seemed interesting to evaluate this development across time by performing a repeated measures analysis for all the variables assessed at the three time points.

Mediation Analyses. In order to confirm the third and fourth hypotheses directly and the first and second hypotheses indirectly, mediation analyses were computed with AMOS 18 by following the product-of-coefficients strategy with bootstrapping to test the strength and significance of the indirect effect (Shrout \& Bolger, 2002). In the present study the 95 per cent confidence interval of the indirect effect was obtained with 5,000 bootstrap resamples. Time 1 measurements of the dispositional variables (external causal attributions and implicit theories of cultural intelligence) were specified as independent variables (IV); time 2 measurements of the psychosocial variables (perceived social support and cultural identity) were specified as the mediators (MV); and time 3 measurement of acculturative stress was specified as the dependent variable (DV).

Structural Equation Modelling (SEM). In order to confirm a longitudi- nal predictive model of acculturative stress in both immigrant and native samples with all of the study's variables (global aim), a multigroup analysis SEM (an autoregressive model with longitudinal and contemporaneous relations, as suggested by Lockhart, MacKinnon, \& Ohlrich, 2011) testing for the equivalence of the longitudinal causal structure in both groups was performed with AMOS 18 by following the manual multistep proposed by Byrne (2009). Moreover, we included age as a covariate to control for age variation (range: $12-18$ years).

\section{RESULTS}

\section{Preliminary Analyses}

In the general sample, and in each evaluation, acculturative stress was significantly and consistently correlated with all of the variables, and implicit 
theories of cultural intelligence were significantly and consistently correlated with cultural identity. Moreover, external causal attributions were significantly and consistently correlated with perceived social support, and cultural identity was significantly and consistently correlated with perceived social support. All of the correlations were in the expected direction (see Table 1) and generally remained in the immigrant and native samples (see Table 2).

In order to analyse the changes in the variables over time, we performed a repeated measures analysis (see Figure 2). The results revealed significant changes over time for acculturative stress $\left(F(2,289)=92.82, p<.01, \mathrm{~h}^{2}=.39\right)$ and perceived social support $\left(F(2,289)=141.72, p<.01, \mathrm{~h}^{2}=.49\right)$. Bonferroni analysis showed that significant differences occurred between each evaluation for both acculturative stress $(p<.01)$ and perceived social support $(p<.01)$. No significant differences were found for cultural identity over time $(F(2$, $289)=.37, n s, h^{2}=.01$ ). When comparing natives and immigrants, significant differences were found between the groups for the evolution of acculturative stress over time $\left(F(1,289)=4.00, p<.02, \mathrm{~h}^{2}=.03\right)$. However, for the evolution of perceived social support $\left(F(2,289)=.89, n s, \mathrm{~h}^{2}=.01\right)$ and cultural identity over time $\left(F(2,289)=.35, n s, \mathrm{~h}^{2}=.01\right)$, no significant differences were found between natives and immigrants. Nevertheless, Bonferroni analyses showed that cultural identity $(p<.05)$ and acculturative stress $(p<.01)$ levels were significantly higher in immigrants than in natives, and that perceived social support $(p<.01)$ was significantly lower.

\section{Mediation Analyses}

To directly examine Hypothesis 3 (the mediating role of perceived social support between causal attributions and acculturative stress), Hypothesis 4 (the mediating role of cultural identity between implicit theories of cultural intelligence and acculturative stress), and indirectly Hypotheses 1 (the predictive role of implicit theories of cultural intelligence on acculturative stress) and 2 (the predictive role of causal attributions on acculturative stress), mediating analysis with bootstrapping was performed. Dispositional variables (external causal attributions and implicit theories of cultural intelligence) of the first measurement point were specified as independent variables (IV); psychosocial variables (perceived social support and cultural identity) of the second measurement point were specified as the mediators (MV); and acculturative stress of the third measurement point was specified as the dependent variable (DV).

The results shown in Table 3 indicate that the 95 per cent confidence interval for the two indirect effects did not include zero, indicating that all of the indirect effects were statistically significant. The direct path from the IV to the MV (b[causal attributions $\rightarrow$ perceived social support] $=-.16$, 
TABLE 1

Correlations, Means, Standard Deviations, and Alpha Reliabilities for all the Study Variables of the General Sample at each Time Point

\begin{tabular}{|c|c|c|c|c|c|c|c|c|c|c|c|c|c|}
\hline & 1 & 2 & 3 & 4 & 5 & 6 & 7 & 8 & 9 & 10 & 11 & Mean & $\mathrm{SD}$ \\
\hline $\begin{array}{l}\text { 1. Implicit theories of } \\
\text { cultural intelligence }\end{array}$ & .74 & & & & & & & & & & & 3.54 & 1.12 \\
\hline 2. External causal & .11 & .66 & & & & & & & & & & 2.83 & .88 \\
\hline
\end{tabular}

attributions

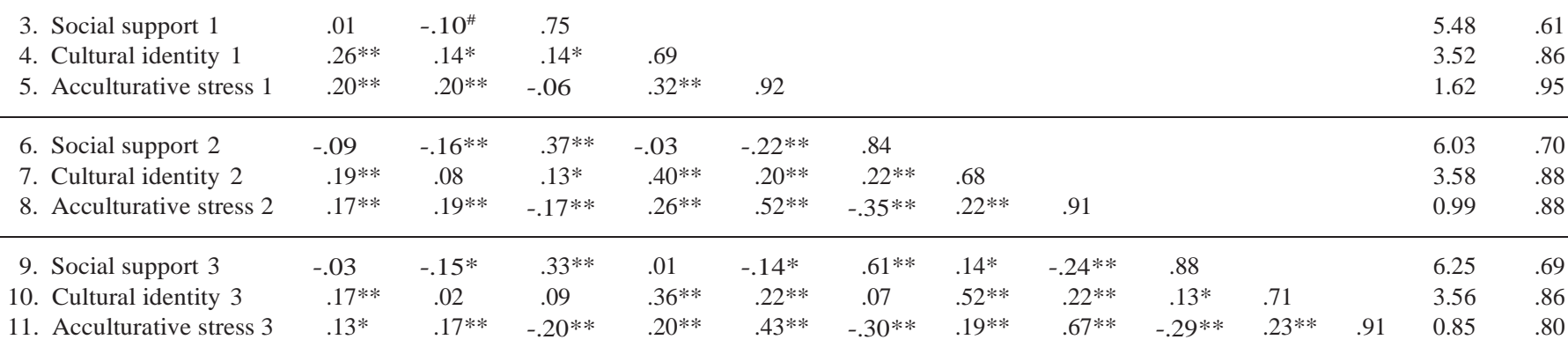

${ }^{\#} p<.09 ; * p<.05 ; * * p<.01$; alphas are on the diagonal. 
TABLE 2

Correlations, Means and Standard Deviations of the Immigrant and Native Samples for all the Study Variables at each TimePoint

\begin{tabular}{|c|c|c|c|c|c|c|c|c|c|c|c|c|c|c|c|}
\hline & \multicolumn{2}{|c|}{ Natives } & \multirow[b]{2}{*}{1} & \multirow[b]{2}{*}{2} & \multirow[b]{2}{*}{3} & \multirow[b]{2}{*}{4} & \multirow[b]{2}{*}{5} & \multirow[b]{2}{*}{6} & \multirow[b]{2}{*}{7} & \multirow[b]{2}{*}{8} & \multirow[b]{2}{*}{9} & \multirow[b]{2}{*}{10} & \multirow[b]{2}{*}{11} & \multicolumn{2}{|c|}{ Immigrants } \\
\hline & M & $\mathrm{SD}$ & & & & & & & & & & & & M & SD \\
\hline Implicit theories of & 3.49 & 1.12 & - & .12 & .08 & $.35^{* *}$ & $.24 * *$ & -.14 & $.19 *$ & $.21^{*}$ & -.07 & $.17^{\#}$ & .10 & 3.61 & 1.12 \\
\hline $\begin{array}{l}\text { cultural intelligence } \\
\text { External causal } \\
\text { attributions }\end{array}$ & 2.76 & .87 & .09 & - & -.13 & -.01 & $.21^{*}$ & -.07 & .10 & $.19 *$ & -.07 & -.10 & .14 & 2.92 & .89 \\
\hline Social support 1 & 5.55 & .59 & -.03 & -.06 & - & $.27 *$ & -.05 & $.25^{* *}$ & .12 & -.10 & $.35^{* *}$ & .08 & $-.18 *$ & 5.39 & .62 \\
\hline Cultural identity 1 & 3.44 & .91 & $.20 * *$ & $.22 * *$ & .08 & - & $.23 *$ & .03 & $.57 * *$ & $.18 *$ & $.17^{\#}$ & $.50 * *$ & .15 & 3.64 & .78 \\
\hline Acculturative stress 1 & 1.49 & .99 & $.17^{*}$ & $.17^{*}$ & -.04 & $.35^{* *}$ & - & $-.20 *$ & $.29 * *$ & $.50 * *$ & $-.18 *$ & .11 & $.36^{* *}$ & 1.82 & .88 \\
\hline Social support 2 & 6.13 & .60 & -.03 & $-.22 * *$ & $.45^{* *}$ & -.03 & $-.19 * *$ & - & $.18^{*}$ & $-.41 * *$ & $.68 * *$ & .12 & $-.33 * *$ & 5.88 & .80 \\
\hline Cultural identity 2 & 3.53 & .88 & $.19 *$ & .05 & $.14^{\#}$ & $.29 * *$ & $.13^{\#}$ & $.28 * *$ & - & $.26 * *$ & $.17^{\#}$ & $.55^{* *}$ & $.22 *$ & 3.64 & .89 \\
\hline Acculturative stress 2 & 0.73 & .75 & .11 & $.16^{*}$ & $-.17^{*}$ & $.28 * *$ & $.52 * *$ & $-.21 * *$ & $.17 *$ & - & $-.30 * *$ & .14 & $.63^{* *}$ & 1.35 & .94 \\
\hline Social support 3 & 6.35 & .62 & .02 & $-.19 *$ & $.29 * *$ & -.06 & -.06 & $.51^{* *}$ & $.15^{*}$ & -.07 & - & $.21 *$ & $-.31 * *$ & 6.09 & .76 \\
\hline Cultural identity 3 & 3.50 & .87 & $.17 *$ & .09 & .12 & $.26 * *$ & $.26 * *$ & .06 & $.49 * *$ & $.26^{* *}$ & .11 & - & $.17^{\#}$ & 3.66 & .84 \\
\hline Acculturative stress 3 & 0.61 & .65 & $.14^{\#}$ & $.15^{*}$ & $-.15^{*}$ & $.120^{*}$ & $.45^{* *}$ & $-.18 *$ & $.15^{*}$ & $.62 * *$ & $-.16 *$ & $.24 * *$ & - & 1.21 & .87 \\
\hline
\end{tabular}

${ }^{\#} p<.09 ; *^{*} p<.05 ; * * p<.01$; upper triangle shows the immigrant sample correlations $(N=173)$ : lower triangle shows the native sample correlations $(N=119)$. 


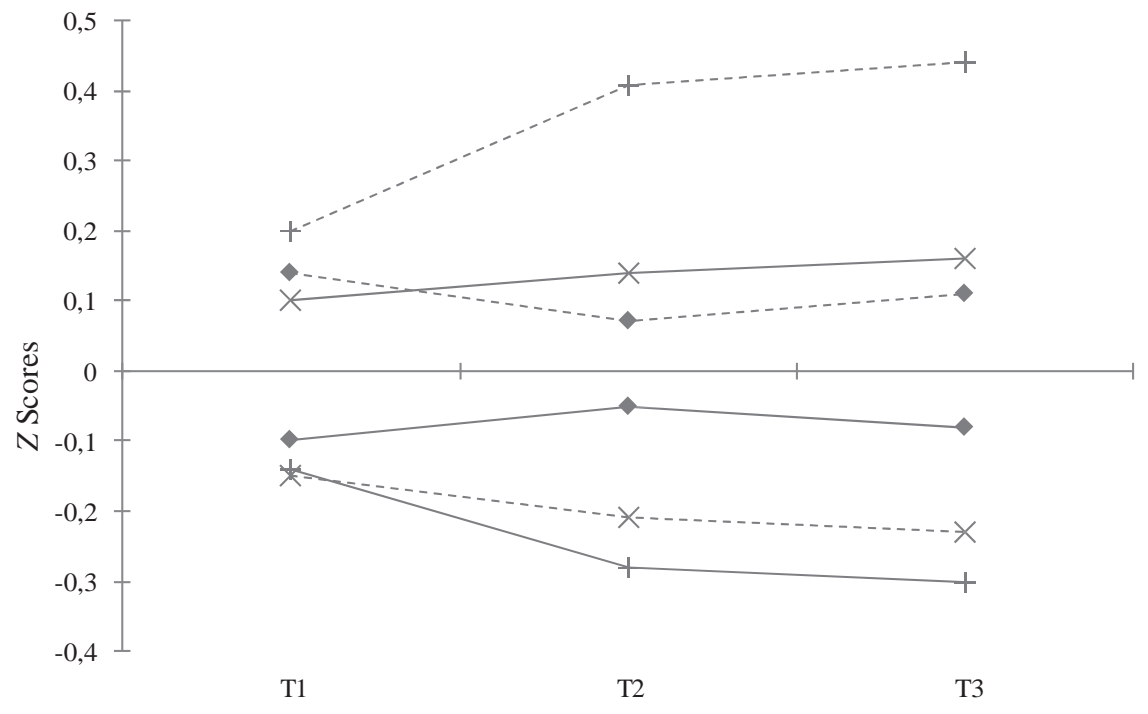

$$
\begin{aligned}
& \longrightarrow \text { Natives' cultural identity } \\
& \longrightarrow \text { Immigrants' cultural identity } \\
& \longrightarrow \text { Natives' perceived social support } \\
& \longrightarrow \text { Immigrants' perceived social support } \\
& \longrightarrow \text { Natives' acculturative stress } \\
& + \text { Immigrants' acculturative stress }
\end{aligned}
$$

FIGURE 2. The evolution of natives' and immigrants' acculturative stress, cultural identity, and perceived social support over time.

$p<.01$; b [implicit theories of cultural intelligence $\rightarrow$ cultural identity $]=.19$, $p<.001$ ), and from the MV to acculturative stress (b[perceived social support $\rightarrow$ acculturative stress] $=-.34, \quad p<.001 ; \mathrm{b}$ [cultural identity $\rightarrow$ acculturative stress $]=.24, p<.001$ ) had significant weights but the direct path from the IV to acculturative stress did not (b[causal attributions $\rightarrow$ acculturative stress $]=.09, n s ; \mathrm{b}$ [implicit theories of cultural intelligence $\rightarrow$ acculturative stress] $=.04, n s)$. Therefore, following Rucker, Preacher, Tormala, and Petty (2011), those results confirm (a) the hypotheses about the mediating role of our variables, and (b) that the likelihood of any additional mediator is probable for those mediating roles. It is noteworthy that those results confirmed our third and fourth hypotheses but not the first and the second. 
TABLE 3

Bootstrap Analyses of the Magnitude and Statistical Significance of Indirect Effects

\begin{tabular}{|c|c|c|c|c|c|}
\hline $\begin{array}{l}\text { Mediational } \\
\text { variables }\end{array}$ & $\begin{array}{c}\text { Dependent } \\
\text { variable }\end{array}$ & $\begin{array}{l}\text { B standardised } \\
\text { indirecteffect }\end{array}$ & $\begin{array}{c}\text { B mean } \\
\text { indirect } \\
\text { effect }^{\mathrm{a}}\end{array}$ & $\begin{array}{l}\text { SE of } \\
\text { mean }^{\mathrm{a}}\end{array}$ & $\begin{array}{c}\text { 95\% confidence } \\
\text { interval mean } \\
\text { indirect effect } \\
\text { (lower and upper) }\end{array}$ \\
\hline PSS $\rightarrow$ & AS & $(-.16) ¥(-.34)=.05$ & .05 & .02 & .02 to .09 \\
\hline $\mathrm{CI} \rightarrow$ & AS & $(.19) ¥(.24)=.05$ & .03 & .01 & .01 to .07 \\
\hline
\end{tabular}

Note: PSS = time 2 measurement of the perceived social support, CI = time 2 measurement of the cultural identity, AS = time 3 measurement of the acculturative stress, SE = Standard error.

a These values are based on unstandardised path coefficients.

\section{Structural Equation Modelling Analysis}

In order to confirm all our hypotheses and the hypothesised predictive longitudinal model of acculturative stress for the general sample and for both the native and the immigrant samples, a multigroup analysis SEM was performed, testing for the equivalence of the longitudinal causal structure in both groups.

Stage One: Testing for the Validity of the Model for the Entire Sample and for Each Group Separately. Three separate SEM were conducted as a prerequisite to test whether the hypothesised model fit each data set. The goodness-of-fit tests revealed that the model was well-fitted to the general sample, i.e. the combined sample of natives and immigrants $\left(c^{2}(36,292)=\right.$ 67.90; RMSEA = .05 (95\% confidence interval $=[.03, .07])$; $\mathrm{CFI}=.96$; and GFI $=.96)$. The model was also well-fitted to both the native $\left(\mathrm{c}^{2}(36,173)=\right.$ 59.66; RMSEA = .06 (95\% confidence interval $=[.03, .09])$; CFI = .94; and GFI $=.95)$ and the immigrant samples $\left(c^{2}(36,119)=48.28\right.$; RMSEA $=.05$ $(95 \%$ confidence interval $=[.01, .09])$; CFI $=.96$; and GFI $=.94)$. Since the adequacy of the model was validated for the two independent groups (natives and immigrants), the model was identically specified for each group as a baseline model for further invariance tests.

Stage Two: Testing for Multi-Group Invariance. Global Fit of the Baseline Model across Natives and Immigrants Simultaneously. We again tested the goodness-of-fit of the model across the two groups together. The analysis showed that the baseline model still represented a fairly good fit: $\left(\mathrm{c}^{2}(72,173)\right.$ $=107.95$; RMSEA $=.04$ (95\% confidence interval $=[.02, .06])$; CFI $=.95$; and 


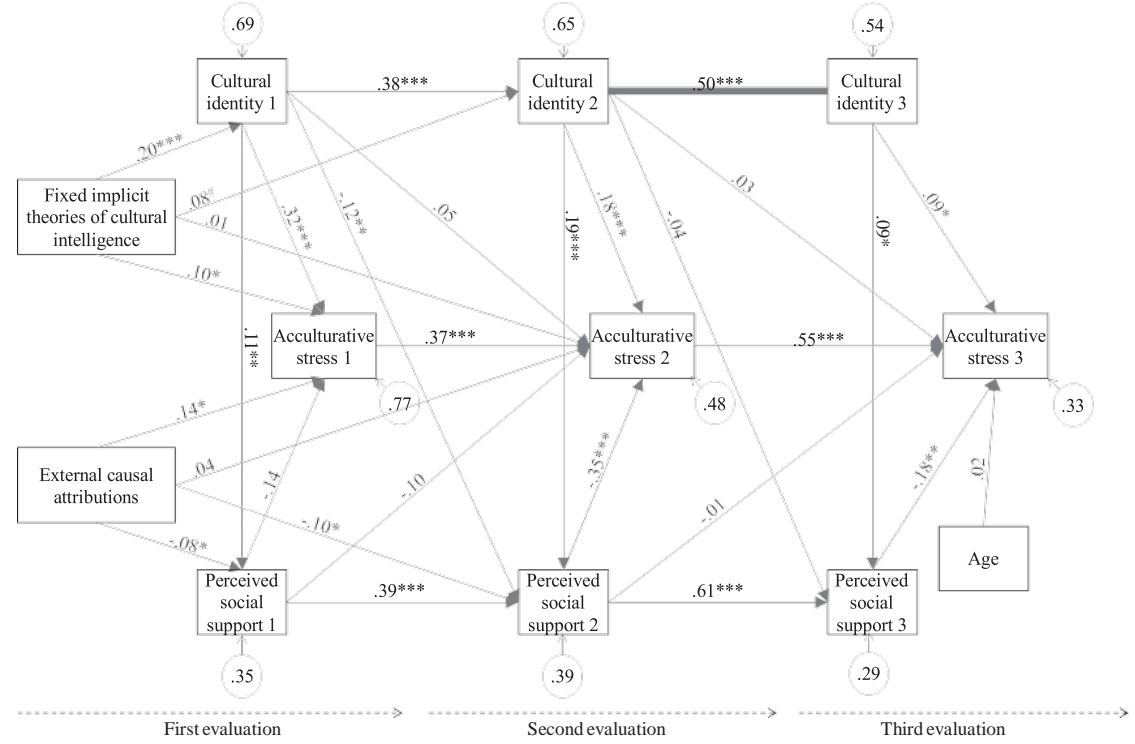

FIGURE 3. Longitudinal predictive model confirmed to be equal across the two samples. Numbers reflect the beta coefficient of the relations of the general model.

${ }^{*} \mathrm{p}<.09 ; * \mathrm{p}<.05 ; * * \mathrm{p}<.01 ; * * * \mathrm{p}<.001$.

GFI $=.94)$. The chi-square value and degree of freedom for this unconstrained multigroup model served as an initial baseline model for further subsequently constrained models.

Testing for Invariance of Loading across the Two Groups. A specified model in which all loadings were constrained to be equal across the two groups $\left(c^{2}(104,173)=139.12\right.$; RMSEA $=.03(95 \%$ confidence interval $=[.02$, $.05]$ ); CFI $=.95$; GFI $=.93$ ) was compared with the baseline model. The chi-square comparison test between the two models yielded non-significance $\left(\mathrm{Dc}^{2}{ }_{(31)}=31.17, n s\right)$, and so the equivalence of all loadings across the two

groups was accepted. With this result, the invariance of the model was assumed and thus our predictive model was in part confirmed: most of the relations were significant. This means that the hypotheses were partially confirmed. The control variable age did not have a direct effect on acculturative stress. Figure 3 represents the general model assumed for the two groups together, i.e. the combined sample $\left(c^{2}(36,292)=67.90\right.$; RMSEA $=.05(95 \%$ 
confidence interval $=[.03, .07])$; CFI $=.96$; and GFI $=.96$ ) 


\section{DISCUSSION}

The results of this study showed that the four independent variables that were analysed (implicit theories of cultural intelligence, causal attributions, perceived social support, and cultural identity) form a longitudinal model predictor of acculturative stress available for both natives and immigrants. In this model, both of the dispositional variables causal attributions and implicit theories of cultural intelligence act as direct and indirect predictors due to the effects they have on perceived social support and cultural identity, respectively, which in turn act as direct predictors of acculturative stress in line with theCAPS(Mischel\&Shoda, 1995; Mendoza-Dentonet al., 2001). Moreover, and also in accordance with the CAPS (Mischel \& Shoda, 1995; MendozaDenton et al., 2001), the mediating analyses revealed that both cultural identity and perceived social support may act as mediators between implicit theories of cultural intelligence and acculturative stress for the first variable, and between causal attributions and acculturative stress for the second.

Our results are in accordance with Berry's $(2003,2005)$ conceptualisation when he claims that acculturative stress occurs in both immigrants and natives. Indeed, it is interesting to note that, theoretically, the invariance across the two groups in the SEM suggests that for both natives and immigrants the same variables come into play in the development of the acculturative stress processes. It seems that for both groups acculturative stress appears when the same variables emerge, and when they emerge in the same way. Consequently, and with regard to the practical implications, in order to decrease acculturative stress levels in adolescents, it seems relevant to consider all of these variables in professional interventions with native and immigrant adolescents in intercultural contexts. Nevertheless, it is also important to note that, for immigrants, both acculturative stress and some of the variables that promote its appearance are higher than for natives. Those results support others (Berry, 2005; Mejía \& McCarthy, 2010) that affirm that acculturative processes have a greater effect on immigrants than on natives. Therefore, although theoretically acculturative stress processes seem conceptually to mean the same for both groups, it is nevertheless important to pay greater attention to the immigrant group in the professional interventions aimed at decreasing acculturative stress.

With regard to the temporal development of the variables, it is noteworthy that perceived social support increased gradually from year to year, meaning that it evolved in the opposite direction from acculturative stress progress, reflecting the close relation which exists between these two variables. This reinforces the interpretation of social support as a protective factor with regard to stress (Crockett et al., 2007; Martínez et al., 2002) and reveals the importance of perceived social support in the acculturative process. Moreover, although perceived social support increased equally in both natives and 
immigrants, note that perceived social support levels were lower in the immigrant sample than in the native one. Thus, regarding the practical implications, it seems necessary to promote in the classroom high perceived social support levels in both groups, but especially in immigrants. And a way of applying this to practice could be to promote in schools educational interventions such as, for example, the different kinds of peer support programmes (an interesting example is the peer-mentoring programme of Devereux, 2004, oriented towards developing intercultural wisdom in students) that can be adapted to different areas: academic support, socialisation, and, definitely, intercultural socialisation. Such programmes facilitate the consolidation of social support and social support networks for pupils who feel isolated, and they can therefore have a positive effect on the decline of acculturative stress.

Also of note, cultural identity was stable over time. Therefore, although identity can be changed gradually through the influence of sociocultural contexts and life events, it seems that, in accordance with other studies (e.g. Hirschi, 2011), these changes are produced slowly, and identity remains relatively stable over time. Moreover, it is noteworthy that cultural identity was higher in the immigrant group than in the native one. This confirms that cultural identity is of great importance for those groups that are far from their own cultural origins, or for minorities (Páez \& González, 2001; Wilson, 1995) and, therefore, for immigrants. This is even more important if we consider that this study highlights the fact that a high cultural identity predicts high levels of acculturative stress, and that acculturative stress was higher for immigrants. It seems particularly essential, then, to pay special attention to acculturative stress in immigrant adolescents.

With regard to acculturative stress, in line with the hypothesis that it will gradually decline as individuals adapt to their new sociocultural context (e.g. Tartakovsky, 2007; Ying, 2005), this variable decreased gradually from year to year. These results suggest that the time of intercultural contact influences acculturative stress, which seems to decrease as individu- als learn to cope with the demands arising from their acculturative envi- ronment. And, although acculturative stress decreased in both groups, itdecreased less in immigrants, whose stress levels were also higher. These results are consistent with the theory that acculturative processes affect immigrants more than natives (Berry, 2005; Mejía \& McCarthy, 2010). Thus, when suffering from this psychological reaction, it seems that immi- grants are more vulnerable to acculturative stress and that they do not cope as well with acculturative stress over time than natives. Thus, it seems rel- evant to highlight once more the importance of paying special attention to acculturative stress in immigrants.

Moreover, acculturative stress levels of participants were relatively low. This supports Tartakovsky's study (2007). According to an interactionist 
model (Lazarus \& Folkman, 1984) or ecological perspective (Bronfenbrenner, 1989) of stress, these results suggest that adolescents have sufficient psychological resources to cope with the demands of an acculturative context, and that intercultural conditions are (or are interpreted to be) benign. Thus, it seems that adolescents' plasticity as well as the fact that they are constructing their identity while submerged in an intercultural context could assist in their adaptation to pluralistic environments (e.g. Schwartz et al., 2010), establishing the fact that adolescents have more fluid intercul- tural relations, and therefore suffer from less acculturative stress.

With regard to the effects of the dispositional variables, the mediating analyses showed that both implicit theories of cultural intelligence and causal attributions indirectly, but not directly, predicted acculturative stress. The findings indicate that other mediators may be involved in these mediation processes. Results have shown that adolescents with fixed implicit theories of cultural intelligence tended to have a stronger cultural identity, in accordance with previous studies (Bastian \& Haslam, 2008; Chiu et al., 1997; Hong et al., 2001). Therefore, when people think that cultural intelligence cannot be changed, they tend to attribute more importance to the cultural features of their global identity. This theory becomes particularly important if we consider that it seems that high cultural identity levels may predict high acculturative stress levels. Thus, those results are in accordance with previous investigations that have shown that entity theorists tend to adopt helpless patterns (e.g. Dweck, 1999; Rusk \& Rothbaum, 2010). Furthermore, external causal attributions predicted lower levels of perceived social support in adolescents. Those results help to confirm that internal causal attributions facilitate the accessibility of social support (e.g. Zea et al., 1995). Again, this posits a greater value to the results if we consider that high perceived social support seems to predict lower acculturative stress levels. Therefore, those results partially support previous studies that have shown that people with more internal causal attributions experience more control over difficult and stressful situations and cope better with stress than those with external causal attributions (e.g. Arslan et al., 2009; Roddenberry \& Renk, 2010). Consequently, implicit theories of cultural intelligence and causal attributions may have an indirect effect on acculturative stress, judging by the effects they have oncultural identity and perceived social support, respectively, which is consistent with the CAPS (Mischel \& Shoda, 1995; Mendoza-Denton et al., 2001). As a result, regarding the practical implications of the study, in order to reduce acculturative stress in the classroom, teachers and educators should promote incremental views about the world and individuals' capacities on one hand, and internal causal attributions on the other. Many authors have previously demonstrated that implicit theories can be changed andshaped through intervention (see Dweck \& Ehrlinger, 2006, for a review) and, 
moreover, other authors have suggested psychological interventions and programmes to change people's attributional style (e.g. Peters, Constans, \& Mathews, 2011; Riemer \& Bickman, 2011). We think that it would be interesting for adolescents to learn (a) that cultural intelligence is something adaptable, which can increase and develop through intercultural contact; and (b) that the outcomes of acculturative situations result from and can be controlled by their own behaviours. Perhaps one way to teach this type of thinking could be through debates concerning cases of people who have experienced changes in their cultural intelligence, or who are responsible for their situation in this regard. Such debates could be mediated by the teacher and, through this process, adolescents can share their views, learning together in the Zone of Proximal Development (Vygotsky, 1978) that cultural intelligence can be enhanced and that we can control the major events of our lives.

With regard to perceived social support, and in agreement with the findings of Ng and Feldman (2009) and Rodríguez et al. (2007), we found that adolescents with a high cultural identity perceived greater social support. Thus, in accordance with Haslam et al. (2009) and Rodríguez et al. (2007), when they affirmed that sharing a sense of identity with a particular group provides higher perceived social support of this group, we think that, to encourage adolescents to successfully cope with acculturative stress, it may be worthwhile facilitating a more intercultural identity. The identification with different cultural groups may enhance in adolescents their perception of social support provided by the different cultural groups of the society.

Moreover, in accordance with Crockett et al. (2007), our results also partially showed that high perceived social support levels predicted lower acculturative stress levels. Therefore, because causal attributions had a direct effect (when more external, more negative effect) on perceived social support, and because in turn high perceived social support seems to predict higher acculturative stress levels, our results are consistent with the conceptualisation of social support as a protective factor that buffers the effects of stress (Cobb, 1976), as well as with the CAPS (Mischel \& Shoda, 1995; MendozaDenton et al., 2001). In accordance with Gençoz and Astan (2006), causal attributions and perceived social support together subsequently appear to be relevant factors that professionals must take into account in their interventions with adolescents in intercultural contexts, promoting intervention programmes which will maximise perceived social support (strategies to promote the students' social networks, such as the peer support programmes, as we have seen already) and instil more internal causal attributions.

The effect of cultural identity on acculturative stress is also noteworthy; a higher degree of identification with one's own cultural group seems to predict higher levels of acculturative stress. These results were consistent with the studies of Friedlander et al. (2010), Yoo and Lee (2008), and Hovey et al. 
(2006). Thus it seems that attributing greater importance to their cultural identity might make adolescents more likely to perceive acculturative processes as a threat. This effect is important in the socio-educational and psychological fields; it seems that it could be important for educators and psychologists to rethink the current view of cultural identity as a protective factor for acculturative stress. In this sense, Sánchez and Fernández (1993) affirmed that immigrants with stronger cultural identity and weaker identification with their native culture suffered higher levels of acculturative stress. Therefore, we propose that acculturative stress programmes and interventions should focus on building an intercultural and cosmopolitan identity, and enabling people to feel part of not only their own cultural group, but also the diverse society in which they are growing and evolving. This means encouraging the construction of cosmopolitan individuals who identify with the diversity of the society they belong to.

Moreover, from our point of view, promoting a balance between the development of personal, social, and cultural identity could help to maintain identity and, at the same time, help to develop strategies for adapting to social norms and groups. This idea is an extension of Brewer's optimal distinctiveness theory (1991), according to which the individual must find a balance between the different personal, social, and cultural forces that shape his or her identity. In line with Leong and Ward (2011), who stated that "Intergroup contact creates opportunities for people of different backgrounds to understand and appreciate members of other groups" (p. 59), we propose that the promotion of an intercultural social support network could facilitate adolescents' identification with members of the diverse range of cultural groups that make up the society in which they live. Consequently, promotion of more expansive intercultural networks, with the promotion of peer support programmes with adolescents of all cultural backgrounds, for example, could enable adolescents to construct a greater intercultural identity, which could ease their experience of acculturation. In this sense, practical interventions, oriented toward the development of cosmopolitan citizenship and intercultural education, seem to be relevant. This approach aims toward adolescents learning to live both in the local and global world, and feeling part of both, expanding their identity horizons and opening up to the surrounding cultures, feeling part of all of them, as well as part of their own culture. Also worth mentioning is the Alternative Learning Center's (CALA, 2009) resource concerned with interculturalism and related conflicts, which attempts to promote in pupils a true understanding of what culture is, taking into account its permeable and changing nature, and prompting adolescents to open their minds to other cultures. Aguado and del Olmo (2009) also created a guide which is an interesting document for the implementation of intercultural education in schools and the enhancement of intercultural identity in students. We believe that these kinds of programmes could lead to 
a reduction in the possible negative effects of high cultural identity in acculturative stress.

\section{Limitations and FutureResearch}

Although this study has implications for socio-educative and psychological interventions with regard to acculturative stress, it is necessary to highlight its limitations. With regard to the data collection procedure, we had to adapt to the availability of the schools. Therefore, data were collected in three different periods in each of the three consecutive years. In order to control for extraneous variables, it would have been appropriate to collect data in the same month in the three consecutive years.

Moreover, although this study is longitudinal, and therefore has causal implications, the self-reported measures used are vulnerable to social desirability. Although the findings have potentially relevant theoretical and practical implications, it would be interesting in future research to conduct an experimental study to ensure the causal relations of the variables, even if it entailed the loss of the ecological validity obtained in this study.

Also, for greater generalisation and in relation to the elevated drop-out rate of the sample, it would be interesting in future research to make data collection more individualised at times 2 and 3 (for example, by collecting the mobile phone number of students at time 1). This would enable us to avoid losing such student samples, especially in view of the considerable geographical mobility of immigrants. Our study has shown differences between those students who completed the three assessment phases and those who did not. At time 1, some students were at high risk of academic failure and they hada high probability of leaving the academic system and, consequently, our longitudinal study. In future studies aimed at the identification of the predictors of acculturative stress it would be necessary to make attempts to follow this sample in order to give a higher level of generalisation to the conclusions drawn. Moreover, as regards the immigrant group, those who did not complete all three surveys have shown higher levels of acculturative stress than those who did. Given that immigrants who did not finish all three surveys are older than those who did, it would be interesting in future research to explore whether their higher levels of acculturative stress can be explained by the fact that they emigrated when they were older. Indeed, most authors have found that acculturative processes are easier for young people than for adults (e.g. Cheung et al., 2011). And regarding the native group, it also would be worthwhile to follow up the native students who did not complete all three surveys if we take into account that they have shown lower levels of perceived social support in our study. This is in line with studies that have related social support and perceived social support to success (e.g. Hogan et al., 2010; Nabi, 2001). So, follow-up of the native students who did not complete all three 
surveys would be interesting in further studies to evaluate whether the low perceived social support of those native students might be related to their failure at school and acculturation stress while adapting to more diverse peer groups as more immigrant students join their class.

In addition, findings based on the current sample of adolescents may not generalise to the adult population. It could be interesting to compare the first generation and the second generation of immigrants, who may not have had the same behaviour with regard to coping or dealing with acculturative stress and with acculturative situations. In future research, this study could be enhanced to a larger sample which includes not only adolescents, but also adults, and which segregates the immigrant sample into two groups: first and second generation.

Furthermore, some items used to measure cultural identity (Brown, 1998; Cheek et al., 1994) have double-barrelled items (such as "My race or cultural background") and can therefore be confusing, because race and cultural background may not always have the same meaning for all the students assessed. In future studies, it would be interesting to analyse this possible bias of error.

Finally, future research might conduct cross-cultural studies which would enable us to generalise these results and confirm their relevance in other intercultural societies. It would also be of interest to analyse other variables such as self-esteem (Hovey \& Magaña, 2002), attitudes towards the outgroups, the attachment system (Rusk \& Rothbaum, 2010), perceived discrimination, and perceived cultural distance (Zlobina, Basabe, Páez, \& Furnham, 2006). In the past, all these variables have been linked with acculturative stress, and if we consider that the results have indicated that other mediators may be involved in the mediation processes, the inclusion of other variables linked with acculturative stress in the previous literature could possibly increase the explicative power of the model. Other variables of interest in future research on acculturative stress include perception of the effectiveness of the received social support (e.g. Haslam et al., 2004) and the received social support (e.g. Reicher \& Haslam, 2006). It would also be interesting to analyse the "sharing a common identity variable" which is related as we have seen to social support (Haslam et al., 2004), which in turn is related to acculturative stress. This would enable a more collective approach to the study.

\section{Conclusion}

Summarising all of our results, in relation to the theoretical implications of the study, a longitudinal predictive model of acculturative stress, framed in the CAPS (Mishel \& Shoda, 1995; Mendoza-Denton et al., 2001), has been demonstrated for both immigrants and natives, including an analysis of all 
variables involved (implicit theories of cultural intelligence, causal attributions, cultural identity, perceived social support). Moreover, the research showed, with regard to practical implications, that it may be relevant to promote incremental implicit theories of cultural intelligence, internal causal attributions, high perceived social support, an equilibrium between personal, social, and cultural identity, and a more intercultural and cosmopolitan identity in both groups, but especially in immigrants. Therefore, two noteworthy implications for professional interventions are the apparent need to rethink the current conceptualisation of cultural identity as a protective factor for acculturative stress on the one hand, and that it may be appropriateto promote large and mainly multicultural social support networks on the other. This possibly will help adolescents to: (a) feel supported by many people of various cultures; (b) identify with different cultural groups as they learn to manage their intercultural relationships; and consequently (c) learn to cope with acculturative contexts.

\section{REFERENCES}

Aguado, T., \& del Olmo, M. (Eds.) (2009). Intercultural education: Perspectives and proposals. Madrid: Proyecto ALFA. Retrieved from http://www.uned.es/ grupointer/interalfa_book+english.pdf.

Araújo Dawson, B., \& Williams, S.A. (2008). The impact of language status as an acculturative stressor on internalizing and externalizing behaviors among Latino/a children: A longitudinal analysis from school entry through third grade. Journal of Youth Adolescence, 37(4), 399-411.

Arends-Tóth, J., \& Van de Vijver, F.J.R. (2008). Family relationships among immigrants and majority members in the Netherlands: The role of acculturation. Applied Psychology: An International Review, 57(3), 466-487.

Arslan, C., Dilmaç, B., \& Hamarta, E. (2009). Coping with stress and trait anxiety in terms of locus of control: A study with Turkish university students. Social Behavior and Personality, 37(6), 791-800.

Barrera, M., Jr. (1986). Distinctions between social support concepts, measures, and models. American Journal of Community Psychology, 14(4), 413-445.

Bastian, B., \& Haslam, N. (2008). Immigration from the perspective of hosts and immigrants: Roles of psychological essentialism and social identity. Asian Journal of Social Psychology, 11(2), 127-140.

Berry, J.W. (2003). Conceptual approaches to acculturation. In K.M. Chun, P.B. Organista, \& G. Marín (Eds.), Acculturation: Advances in theory, measurement and applied research (pp. 17-37). Washington, DC: American Psychological Association.

Berry, J.W. (2005). Acculturation: Living successfully in two cultures. International Journal of Intercultural Relations, 29(6), 697-712.

Berry, J.W., Phinney, J.S., Sam, D.L., \& Vedder, P. (2006). Immigrant youth: Acculturation, identity, and adaptation. Applied Psychology: An International Review, 55(3), 303-332. 
Blackwell, L., Trzesniewski, K., \& Dweck, C. (2007). Implicit theories of intelligence predict achievement across an adolescent transition: A longitudinal study and an intervention. Child Development, 78(1), 246-263.

Brewer, M.B. (1991). The social self: On being the same and different at the same time. Personality and Social Psychology Bulletin, 17(5), 475-482.

Bronfenbrenner, U. (1989). Ecological systems theory. In R. Vasta (Ed.), Annals of child development (Vol. 6, pp. 187-249). Greenwich, CT: JAIPress.

Brown, J.D. (1998). The Self. Boston, MA: McGraw-Hill.

Byrne, B.M. (2009). Structural equation modeling with Amos: Basic concepts, applications and programming. New York: Routledge.

CALA (Centro Alternativo de Aprendizajes) (2009). Interculturality and conflict. Badajoz: Colectivo Cala.

Cauce, A.M., Hannan, K., \& Sargeant, M. (1992). Life stress, social support and locus of control during early adolescence: Interactive effects. American Journal of Community Psychology, 20,787-798.

Cemalcilar, Z. (2008). A longitudinal study of the adaptation of international students in the United States. Cross-Cultural Psychology, 39(6), 799-804.

Cervone, D. (2005). Personality architecture: Within-person structures and processes. Annual Review of Psychology, 56, 423-452.

Cheek, J.M., Tropp, L.R., Chen, L.C., \& Underwood, M.K. (1994, August). Identity orientations: Personal, social, and collective aspects of identity. Paper presented at the Meeting of the American Psychological Association, Los Angeles, CA.

Cheung, B.Y., Chudek, M., \& Heine, S.J. (2011). Evidence for a sensitive window for acculturation: Younger immigrants report acculturating at a faster rate. Psychological Science, 22, 147-152.

Chiu, C., Dweck, C.S., Tong, Y., \& Fu, H. (1997). Implicit theories and conceptions of morality. Journal of Personality and Social Psychology, 73(5), 923-940.

Cho, Y.B., \& Haslam, N. (2010). Suicidal ideation and distress among immigrant adolescents: The role of acculturation, life stress, and social support. Journal of Youth and Adolescence, 39(4), 370-379.

Cobb, S. (1976). Social support as a moderator of life stress. Psychosomatic Medicine, 38(5), 300-314.

Crockett, L.J., Iturbide, M.I., Torres Stone, R.A., McGinley, M., Rafaelli, M., \& Carlo, G. (2007). Acculturative stress, social support, and coping: Relations to psychological adjustment among Mexican American college students. Cultural Diversity and Ethnic Minority Psychology, 13(4), 347-355.

Daniels, K., \& Guppy, A. (1997). Stressors, locus of control and social support as consequences of affective psychological well-being. Journal ofOccupational Health Psychology, 2(2), 156-174.

Dar-Nimrod, I., \& Heine, S.J. (2011). Genetic essentialism: On the deceptive determinism of DNA. Psychological Bulletin, 137, 800-818.

Devereux, L. (2004). When Harry met Sarita: Using a peer-mentoring program to develop intercultural wisdom in students. In F. Sheehy \& B. Stauble (Eds.), Transforming knowledge into wisdom: Holistic approaches to teaching and learning (pp. 146-154). Milperra, NSW: HERDSA. 
Duarte, C.S., Bird, H.R., Shrout, P.E., Wu, P., Lewis-Fernandez, R., Shen, S., \& Canino, G. (2008). Culture and psychiatric symptoms in Puerto Rican children: Longitudinal results from one ethnic group in two contexts. Journal of Child Psychology and Psychiatry, 49(5), 563-572.

Duru, E., \& Poyrazli, S. (2007). Personality dimensions, psychosocial-demographic variables, and English language competency in predicting level of acculturative stress among Turkish international students. International Journal of Stress Management, 14(1), 99-110.

Dweck, C.S. (1999). Self-theories: Their role in motivation, personality, and development. Philadelphia, PA: Psychology Press/Taylor and Francis.

Dweck, C.S., Chiu, C., \& Hong, Y. (1995). Implicit theories and their role in judgments and reactions: A world from two perspectives. Psychological Inquiry, 6(4), 267-285.

Dweck, C., \& Ehrlinger, J. (2006). Implicit theories and conflict resolution. In M. Deutsch, P. Coleman, \& E. Marcus (Eds.), The handbook of conflict resolution: Theory and practice (Vol. 2, pp. 317-330). San Francisco, CA: Jossey-Bass.

Earley, P.C., \& Mosakowski, E. (2004). Cultural intelligence. Harvard Business Review, 82(10), 139-146.

Faller, H., Schilling, S., \& Lang, H. (1995). Causal attribution and adaptation among lung cancer patients. Journal of Psychosomatic Research, 39(5), 619-627.

Friedlander, M.L., Friedman, M.L., Miller, M.J., Ellis, M.V., Friedlander, L.K., \& Mikhaylov, V.G. (2010). Introducing a brief measure of cultural and religious identification in American Jewish identity. Journal of Counseling Psychology, 57(3), 345-360.

Fuligini, A. (2001). A comparative longitudinal approach to acculturation among children from immigrant families. Harvard Educational Review, 71(3), 566579.

Gençoz, T., \& Astan, G. (2006). Social support, locus of control, and depressive symptoms in hemodialysis patients. Scandinavian Journal of Psychology, 47(3), 203-208.

Green, B., \& Rodgers, A. (2001). Determinants of social support among low-income mothers: A longitudinal analysis. American Journal of Community Psychology, 29(3), 419-442.

Griffith, J. (1984). Emotional support providers and psychological distress among Anglo- and Mexican-Americans. Community Mental Health Journal, 20(3), 182 201.

Haslam, S.A., Jetten, J., O’Brien, A., \& Jacobs, E. (2004). Social identity, social influence and reactions to potentially stressful tasks: Support for the selfcategorization model of stress. Stress and Health, 20(1), 3-9.

Haslam, S.A., Jetten, J., Postmes, T., \& Haslam, C. (2009). Social identity, health and well-being: An emerging agenda for applied psychology. Applied Psychology: An International Review, 58(1), 1-23.

Haslam, S.A., O’Brien, A., Jetten, J., Vormedal, K., \& Penna, S. (2005). Taking the strain: Social identity, social support, and the experience of stress. British Journal of Social Psychology, 44(3), 355-370. 
Heine, S.J., Kitayama, S., Lehman, D.R., Takata, T., Ide, E., Leung, C., \& Matsumoto, H. (2001). Divergent consequences of success and failure in Japan and North America: An investigation of self-improving motivations and malleable selves. Journal of Personality and Social Psychology, 81(4), 599-615.

Heine, S.J., \& Ruby, M.B. (2010). Cultural psychology. Wiley Interdisciplinary Reviews: Cognitive Science, 1(2), 254-266.

Henly, J., Danziger, S., \& Offer, S. (2005). The contribution of social support to the material well-being of low-income families. Journal of Marriage and Family, 67, $122-140$.

Hirschi, A. (2011). Vocational identity as a mediator of the relationship between core self-evaluations and life and job satisfaction. Applied Psychology: An International Review, 60(4), 622-644.

Hogan, M.J., Parker, J.D.A., Wiener, J., Watters, C., Wood, L.M., \& Oke, A. (2010). Academic success in adolescence: Relationship among verbal IQ, social support and emotional intelligence. Australian Journal of Psychology, 62(1), 30-41.

Hong, Y., Chan, G., Chiu, C., Wong, R.Y.M., Hansen, I.G., Lee, S., Tong, Y., \& Fu, H. (2003). How are social identities linked to self-conception and intergroup orientation? The moderating effect of implicit theories. Journal of Personalityand Social Psychology, 85(6), 1147-1160.

Hong, Y., Ip, G., Chiu, C.Y., Morris, M.W., \& Menon, T. (2001). Cultural identity and dynamic construction of the self: Collective duties and individual rights in Chinese and American cultures. Social Cognition, 19(3), 251-268.

Hovey, J.D., Kim, S.E., \& Seligman, L.D. (2006). The influences of cultural values, ethnic identity, and language use on the mental health of Korean American college students. Journal of Psychology, 140(5), 499-511.

Hovey, J.D., \& Magaña, C.G. (2002). Cognitive, affective, and physiological expressions of anxiety symptomatology among Mexican migrant farmworkers: Predictors and generational differences. Community Mental Health Journal, 38(3), 223-237.

Kaplan, A., \& Maehr, M.L. (2007). The contributions and prospects of goal orientation theory. Educational Psychology Review, 19(2), 91-110.

Kellezi, B., Reicher, S., \& Cassidy, C. (2009). Surviving the Kosovo conflict: A study of social identity, appraisal of extreme events, and mental well-being. Applied Psychology: An International Review, 58(1), 59-83.

Lakey, B., \& Cassady, P.B. (1990). Cognitive processes in perceived social support. Journal of Personality and Social Psychology, 29, 475-486.

Lazarus, R.S., \& Folkman, S. (1984). Stress, appraisal and coping. New York: Springer.

Leong, C.H., \& Ward, C. (2011). Intergroup perceptions and attitudes toward immigrants in a culturally plural society. Applied Psychology: An International Review, 60(1), 46-65.

Levy, S., Stroessner, S., \& Dweck, C. (1998). Stereotype formation andendorsement: The role of implicit theories. Journal of Personality and Social Psychology, 74(6), 1421-1436.

Lipsicas, C.B., \& Mäkinen, I.H. (2010). Immigration and suicidality in the young. Canadian Journal of Psychiatry: Revue Canadienne de Psychiatrie, 55(5), 274-281. 
Lockhart, G., MacKinnon, D.P., \& Ohlrich, V. (2011). Mediation analysis in psychosomatic medicine research. Psychosomatic Medicine, 73(1), 29-43.

Martínez, M.F., García, M., \& Maya, I. (2002). Social support and locus of control as predictors of psychological well-being in Moroccan and Peruvian immigrant women in Spain. International Journal of Intercultural Relations, 26(3), 287 310.

Mejía, O.L., \& McCarthy, C.J. (2010). Acculturative stress, depression, and anxiety in migrant farmwork college students of Mexican heritage. International Journal of Stress Management, 17(1), 1-20.

Mena, F.J., Padilla, A.M., \& Maldonado, M. (1987). Acculturative stress and specific coping strategies among immigrant and later generation college students. Hispanic Journal of Behavioral Sciences, 9(2), 207-225.

Mendoza-Denton, R., Ayduk, O., Mischel, W., Shoda, Y., \& Testa, A. (2001). Person $\mathrm{X}$ situation interactionism in self-encoding (I am . . . when . . .): Implications for affect regulation and social information processing. Journal of Personality and Social Psychology, 80(4), 533-544.

Mischel W., \& Shoda, Y. (1995). A cognitive-affective system theory of personality: Reconceptualizing situations, dispositions, dynamics, and invariance in personality structure. Psychological Review, 102(2), 246-268.

Nabi, G.R. (2001). The relationship between HRM, social support and subjective career success among men and women. International Journal of Manpower, 22(5), 457-474.

Ng, T.W.H., \& Feldman, D.C. (2009). Personality, social relationships, and vocational indecision among college students: The mediating effects of identity construction. Career Development International, 14(4-5), 309-332.

No, S., Hong, Y., Liao, H., Lee, K., Wood, D., \& Chao, M.M. (2008). Lay theory of race affects and moderates Asian Americans' responses toward American culture. Journal of Personality and Social Psychology, 94(4), 991-1004.

Oba, S., Takatsuka, N., Nagata, C., Nagao, Y., Yamamoto, S., Shibuya, C., Kashiki, Y., \& Shimizu, H. (2009). Causal attributions to epidemiological risk factors and their associations to later psychological adjustment among Japanese breast cancer patients. Supportive Care International, 17(1), 3-9.

Páez, D., \& González, J.L. (2001). Culture and social psychology. Psicothema, 12(1), 6-15.

Paradies, Y. (2006). A systematic review of empirical research on self-reported racism and health. International Journal of Epidemiology, 35(4), 888-901.

Paukert, A.L., Pettit, J.W., Perez, M., \& Walker, R.L. (2006). Affective and attributional features of acculturative stress among ethnic minority college students. Journal of Psychology: Interdisciplinary and Applied, 140(5), 405-419.

Peters, K.D., Constans, J.I., \& Mathews, A. (2011). Experimental modification of attribution processes. Journal of Abnormal Psychology, 120(1), 168-173.

Reicher, S., \& Haslam, S.A. (2006). Tyranny revisited: Groups, psychological wellbeing and the health of societies. Psychologist, 19(3), 146-150.

Riemer, M., \& Bickman, L. (2011). Using program theory to link social psychology and program evaluation. In M.M. Mark, S.I. Donaldson, \& B. Campbell (Eds.), Social psychology and evaluation (pp. 104-138). New York: Guilford Press. 
Roddenberry, A., \& Renk, K. (2010). Locus of control and self-efficacy: Potential mediators of stress, illness, and utilization of health services in college students. Child Psychiatry \& Human Development, 41(4), 353-370.

Rodríguez, N., Mira, C.B., Páez, N.D., \& Myers, H.F. (2007). Exploring the complexities of familism and acculturation: Central constructs for people of Mexican origin. American Journal of Community Psychology, 39(1-2), 61-77.

Ronen, S., \& Baldwin, M.W. (2010). Hypersensitivity to social rejection and perceived stress as mediators between attachment anxiety and future burnout: A prospective analysis. Applied Psychology: An International Review, 59, 380-403.

Rucker, D.D., Preacher, K.J., Tormala, Z.L., \& Petty, R.E. (2011). Mediation analysis in social psychology: Current practices and new recommendations. Social and Personality Psychology Compass, 5, 359-371.

Rusk, N., \& Rothbaum, F. (2010). From stress to learning: Attachment theory meets goal orientation theory. Review of General Psychology, 14(1), 31-43.

Sánchez, J.I., \& Fernández, D.M. (1993). Acculturative stress among Hispanics: A bidimensional model of ethnic identification. Journal of Applied Social Psychology, 23(8), 654-668.

Sarason, I.G., Pierce, G.R., \& Sarason, B.R. (1990). Social support and interactional processes: A triadic hypothesis. Journal of Social and Personal Relationships, 7, 495-506.

Schwartz, S.J., Unger, J.B., Zamboanga, J.S., \& Szapocznik, J. (2010). Rethinking the concept of acculturation: Implications for theory and research. American Psychologist, 65(4), 237-251.

Scott, S.L., Carper, T.M., Middleton, M., White, R., Renk, K., \& Grills-Taquechel, A. (2010). Relationships among locus of control, coping behaviors, and levels of worry following exposure to hurricanes. Journal of Loss and Trauma, 15(2), 123-137.

Shin, H.S., Han, H.R., \& Kim, M.T. (2007). Predictors of psychological well-being amongst Korean immigrants to the United States: A structured interview study. International Journal of Nursing Studies, 44(3), 415-426.

Shoda, Y., \& Mischel, W. (2006). Applying meta-theory to achieve generalizability and precision in personality science. Applied Psychology: An International Review, 55(3), 439-452.

Shrout, P.E., \& Bolger, N. (2002). Mediation in experimental and nonexperimental studies: New procedures and recommendations. Psychological Methods, 7, 422445.

Shweder, R.A., \& Miller, J.G. (1985). The social construction of the person: How is it possible? In K. Gergen \& K. Davis (Eds.), The social construction of the person (pp. 41-69). New York: Springer-Verlag.

Sinibaldi, G.J. (2001). Fear, support, and stigma on VIH people. Doctoral dissertation, Family Therapy Institute, CENCALLI, México.

Siu, O., Spector, P.E., Cooper, C.L., Lu, L., \& Yu, S. (2002). Managerial stress in greater China: The direct and moderator effects of coping strategies and work locus of control. Applied Psychology: An International Review, 51(4), 608-632.

Tabernero, C., \& Wood, R.E. (1999). Implicit theories versus the social construal of ability in self-regulation and performance on a complex task. Organizational Behaviour and Human Decision Processes, 78(2), 104-127. 
Tajfel, H. (1981). Human groups and social categories. Cambridge: Cambridge University Press.

Tamir, M., John, O.P., Srivastava, S., \& Gross, J.J. (2007). Implicit theories of emotion: Affective and social outcomes across a major life transition. Journal of Personality and Social Psychology, 92(4), 731-744.

Tartakovsky, E. (2007). A longitudinal study of acculturative stress and homesickness: High-school adolescents immigrating from Russia and Ukraine to Israel without parents. Social Psychiatry and Psychiatric Epidemiology, 42(6), 485-494.

Thomas, D.C., Elron, E., Stahl, G., Ekelund, B.Z., Ravlin, E.C., Cerdin, J.L., Poelmans, S., Brislin, R., Pekerti, A., Aycan, Z., Maznevski, M., Au, K., \& Lazarova, M.B. (2008). Cultural intelligence: Domain and assessment. International Journal of Cross Cultural Management, 8(2), 123-143.

Tong, E.M.W., \& Chang, W.C. (2008). Group entity belief: An individual difference construct based on implicit theories of social identities. Journal of Personality, 76(4), 707-732.

Tropp, L., \& Wright, S.C. (2001). Ingroup identification as the inclusion of ingroup in the self. Personality and Social Psychology Bulletin, 27(5), 585-600.

VanderZee, K.I., Buunk, B.P., \& Sanderman, R. (1997). Social support, locus of control and psychological well-being. Journal of Applied Social Psychology, 27, 1842-1859.

van Tilburg, M.A.L., Becht, M.C., \& Vingerhoets, A. (2003). Self-reported crying during the menstrual cycle: Sign of discomfort and emotional turmoil or erroneous beliefs? Journal of Psychosomatic Obstetrics and Gynecology, 24(4), 247-255.

Vygotsky, L.S. (1978). Mind in society. Cambridge, MA: Harvard University Press. Walker, R.L. (2007). Acculturation and acculturative stress as indicators for suicide risk among African Americans. American Journal of Orthopsychiatry, 77(3), 386391.

Weiner, B. (1985). An attributional theory of achievement motivation and emotion. Psychological Review, 92(4), 548-573.

Weinert, C. (1987). A social support measure: PRQ85. Nursing Research, 36(5), 273-277.

Weinert, C. (2003). Measuring social support: PRQ2000. In O. Strickland \& G. Dilory (Eds.), Measurement of nursing outcomes: Self-care and coping (pp. 161172). New York: Springer Publishing Company.

Wilson, R. (1995). Maya resurgence in Guatemala. Norman, OK: University of Oklahoma Press.

Ying, Y.-W. (2005). Variation in acculturative stressors over time: A study of Taiwanese students in the United States. International Journal of Intercultural Relations, 29(1), 59-71.

Ying, Y.-W., \& Han, M. (2006). The contribution of personality, acculturative stressors, and social affiliation to adjustment: A longitudinal study of Taiwanese students in the United States. International Journal of Intercultural Relations, 30(5), 623-635.

Yoo, H.C., \& Lee, R.M. (2008). Does ethnic identity buffer or exacerbate the effects of frequent racial discrimination on situational well-being of Asian Americans? Journal of Counseling Psychology, 55(1), 63-74. 
Zapf, D., Dormann, C., \& Frese, M. (1996). Longitudinal studies in organizational stress research: A review of the literature with reference to methodological issues. Journal of Occupational Health Psychology, 1(2), 145-169.

Zea, M.C., Jarama, S.L., \& Bianchi, F.T. (1995). Social support and psychosocial competence: Explaining the adaptation to college of ethnically diverse students. American Journal of Community Psychology, 23(4), 509-531.

Zlobina, A., Basabe, N., Páez, D., \& Furnham, A. (2006). Sociocultural adjustment of immigrants: Universal and group-specific predictors. International Journal of Intercultural Relations, 30, 195-211.

\section{APPENDIX}

\section{Implicit Theories of Cultural Intelligence Scale}

We are interested in knowing your ideas with regard to cultural intelligence. Cultural intelligence is the ability to adapt to new cultures. Using the scale below, please indicate the extent to which you agree or disagree with each of the following statements by writing the number that corresponds to your opinion.

1. Everyone has a certain amount of cultural intelligence, and there is not much that can be done to really change that.

2. Cultural intelligence is something basic about people and it can't be changed very much.

3. To be honest, people can't really change how cultural intelligent they are.

4. Everyone can learn new things, but the important parts of their basic cultural intelligence can't really be changed.

5. People can change even their basic cultural intelligence level considerably. ${ }^{\circledR}$ 